\title{
Historical View on Block Printing Technique and its Used in Bagh Print
}

\author{
Kalam Chouhan* \\ Department of History, Govt. P.G. College, Alirajpur, Madhya Pradesh, India \\ *Corresponding Author: Kalam Chouhan, Department of History, Govt. P.G. College, Alirajpur, \\ Madhya Pradesh, India
}

\begin{abstract}
In this paper the providing history of the block printing techniques and the Bagh block print as an world famous hand block print. Bagh Print is a traditional hand block print with natural colours. Bagh print fabric with replicated geometric and floral compositions with vegetable colours of red and black over a white background is a popular Textile printing product. Bagh print as an excellent product which is a local art form of Madhya Pradesh.
\end{abstract}

Keywords: Wooden Block, Fabric, Vegetable Dyes

\section{INTRODUCTION}

The block printing technique is a very old and first time this used in China over 2,000 years ago. At first block printing was only used for artwork printed on fabric. Later, it was also applied to paper. Block printing is a form of dying and coloring a fabric using wooden blocks .India is one of the largest manufacturers and exporters of block printed fabric in the world. The most important centres for block printing in India are Sanganer, Jaipur, Bagru and Barmer in Rajasthan, Bagh in Madhya Pradesh, Anjar, Deesa, Ahemdabad, Jetpur, Rajkot, Porbandar and Bhavnagar in Gujarat, and Pilakuan and Farukhabad in Uttar Pradesh.

The hand block printed fabrics from Bagh are popularly known as Bagh prints. Bagh is a small tribal town in the Kukshi tehsil of Dhar district of Madhya Pradesh. Legend has it that the town of Bagh, the Baghini River and the nearby Bagh caves (3rd \& 5th century AD, with rich carvings and paintings dedicated to both Hindu as well as Buddhist deities) got their name from the baghs or tigers that inhabited the region. The river of the area Baghini was special It's copper content was high and that would account for all the beautiful deep colors in the fabrics that would be offered from the region. Also, the flowing water would contribute essentially to the dyeing process.

Ismail Sulemanji Khatri was an Indian craftsman, especially known for his invention of the Bagh print.They were originally from Sindh (now in Pakistan), and had since migrated to Marwad in Rajasthan and then to Manavar. With them they brought the block printing technique, which is now the unique Bagh printing style. The khatri community, who comprise the 'chhipas' or printers, came here about 400 years ago from Larkana in Sindh which is famous for its Ajrak prints. He improved upon the red and black dyes previously used and developed new vegetable-based dyes. His primary innovation was creating the Bagh Print on different types of cloth by printing on them.

\section{WOODEN BLOCKS}

Wooden blocks are the main tools used in Bagh printing. These blocks are made of teakwood (Teak wood, locally known as 'Sagwan') slabs purchased form the local markets. Teak provides the perfect base for carving intricate motifs as it is a dense and strong wood. It doesn't absorb water or distort in shape even after years of usage. The craftsmen use a hand-drill arrangement that involves a bow called 'Kamthi' and a driller 'Saarardi, to drill out larger portions of the design voids from the block. For finer carving and finishes they use a variety of chisels of varying shapes and sizes. These tools are also handmade by them according to their requirements. Once prepared, the blocks are immersed in oil for a few days to protect them against warping and insect attacks. This is important since the block is going to be in constant touch with water-based dyes, which make them more vulnerable to decay. 
Some of the block designs covered Nariyal Zaal and Ghevar Zaal based on the Taj Mahal paintings, Saj, Dakmandwa, chameli jasmine, maithir or mushroom, leheriya and jurvaria or small dots on the field. Other innovations introduced by Khatri are: block designs of the jaali pattern from the Taj Mahal and forts and cave in the region.

\section{RAW MATERIALS}

The fabric used by the Khatris may be Bangalori silk (bought from Indore), cotton or grey latha (bought from Indore and Bombay) or silk-cotton mix (bought from Maheshwariin Khargoan district). Silk needs much more delicate handling and care generally a silk cloth takes almost double the time for its completion than does a piece of cotton cloth the same size. Other ingredients such as Cenchura (raw salt), aarandi ka tel (castor oil), grounded goat's dung, Fitkari (alum), Hirakasish or iron sulphate, jaggery, Pomegranate skins, indigo leaves, lime, Sajji, Leaves of Dhavdi, sanchara (rock salt), mengni, Iron sulphate, chiyan (tamarind seed) powder, dhavdakaphool (for shining and fixing) and alizarine (to fasten colours), etc are used in the various processes of printing .

\subsection{Washing and Drying the Fabric Before Printing}

It is first soaked in water for about twelve hours and then suckled with legs to remove the starch. This process is called 'kharakarna'. It is then bleached and washed in 'sanchorapaani' (a mix of rock salt and water). Harada powder (obtained from a type of tree) is mixed in water and the fabric is washed in it for about five minutes. This provides it an off-white/ off-yellow tinge and also aids in strengthening the tones of black and red colors printed later. It is then dried in the sun. About two hundred pieces of fabric are made ready-to-print everyday.

\subsection{Printing}

Ferrous sulphate (used for making black dye) or alum (used for preparing red dye) is first mixed with water. After that 'imli ka chiya' (tamarind seed powder which is now a substitute for glue) is mixed into the alum or iron sulphate solution. A paste right for the consistency of printing is made. Other shades can be created by varying the ratio of different ingredients used. It takes 2-3 hours to prepare these colors. This is for the color to be absorbed properly into the fabric and become 'pakka'.

\section{Process of Dyeing}

Hand block prints are developed by natural colors. Bagh print leads India in the entire world. Bagh layouts are dramatic in the use of black and red alternately on a white background. The black colour is prepared with ferrous sulphate mixed with tamarind seed powder and glue which is cooked in water and stored for use. Each sari takes a minimum of three weeks to complete after the design is printed. During this period, it is washed at least three times and sent to the bhatti/ oven at least twice. Bagh prints are known for their fine quality printing and bright vegetables colors and may be recognized by their geometric repetitive patterns in different variations and colors that are mainly red and black block printed predominantly on white base.

\subsection{Vegetable Dyes}

In Bagh printing, only vegetable dyes are used, the main colors being black and red. For black color, a mixture of harada and iron ore is used. For red, a mixture of alum and dhavda flower is used. These dyes are extracted and prepared locally. Vegetable dyes are eco friendly, skin friendly and non hazardous.

\subsection{Washing and Boiling After Printing}

The next part of the process is to take the printed bundles to be washed in running water. The fabric is first cleansed in flowing water and then beaten against stones. That clears the material of any excess color. This requires a lot of care else stains and smudges would appear on the printed surface. It is then left to dry in the sun.

Once the fabric is dried after washing in the river, it is taken to a huge copper vessel to be boiled. It contains about hundred grams of alizarin (a type of vegetable powder to make the colors fast) and two hundred litres of water. Dhavdikephool (a type of flower) are added to lend shine to the print and prevent froth from damaging the fabric. A single load contains about thirty pieces that have to be boiled for about two hours. This process is called 'bhattikarna'. It is at this stage that the block prints take their actual color. One can see the pinks and purples turning into red and black. The heat from 
under does magic, quite literally. Later, if needed, the off-white base is dyed to bright colors like yellow, green, blue and orange by adding different vegetable dyes. Bleaching is done once again after boiling to remove stains and colors that have bled. One final wash in clean water is done and the printed fabric is laid out in the sun to dry, ready to be worn!

\subsection{The Different Types of Products that are Printed in Bagh Prints}

- Cotton bedcovers in two different sizes for single bed and double bed respectively.

- Saris are printed in different materials like cotton, silk and chiffon.

- Cushion covers mainly in cotton, in different sizes.

- Table covers of different sizes and shapes in cotton material.

- Duppattas and stoles in cotton and silk material.

- Recently, durries printing has also been worked on.

- Salwar suit material and yardage dress material etc

\subsection{Bagh Print Craftsmen and their Achievements}

Trying a new experiment Abdul Kadar Khatri son of Ismail Sulemanji Khatri gave a new look to the dupatta in Bagh print. Abdul Kadar Khatri and his son Arif Khatri and Mohammad Khatri have brought laurels to the State and country at international platform by showcasing their immense talent in Bagh print art in countries like Germany, Oman, Australia, South Africa, Malaysia and Thailand. Mohammed Bilal Khatri son of Mohammed Yusuf Khatri (son of Ismail Sulemanji Khatri) is an also famous Indian young Master craftsman of Bagh Print.

- Recently, Abdul Kadar Khatri has bagged UNESCO and World Craft Council award for Excellence for Handicrafts on silk dupatta adorned with traditional colours in 2018.

- The Art Fund Award in 2015.

- Diploma Award by International Ethnomir "Dialogue of Cultures - united world" in Russia 2014

- Lifetime achievement awards for Handicrafts 2013

- Received the 2010 Shilp Guru Award, the highest award of the Indian Craftsmanship.

- Khatri was awarded the National Award by the Government of India in 2005.

- The State Level Award by Madhya Pradesh 1990

- National Award from former President of India Shri Gyani Zail Singh at the Vigyan Bhavan New Delhi in 1984.

- State Award government of Madhya Pradesh 1978

- State Santavna Award government of Madhya Pradesh 1976

\section{CONCLUSION}

Bagh prints is very old print and this is a hand block print with natural color. In it two main color red $\&$ black .Red color with alum And black color is iron oxide (Corrosion of iron). Bagh prints are known for their fine quality printing and bright vegetables colours and may be recognised by their geometric repetitive patterns in different variations and colors that are mainly red and black block printed predominantly on white base. Khaki and mustard vegetables colors are used for dyeing the fabric after printing. The dynamism of the design which could be derived from the ability of the artisans to change the design pattern to cater the need of the market demand pattern has always attracted the modern market forces.

\section{REFERENCES}

[1] GEOGRAPHICAL INDICATIONS JOURNAL NO.75, Bagh Prints of Madhya Pradesh (Logo )- GI Application No.505, November 26, 2015,

[2] Manik Samwatsar Dange, Asian Resonance VOL.-IV, ISSUE-I, January-2015, 
[3] "Bagh legend Ismail Khatri dies in Dhar district". Times of India. April 29, 2014. Retrieved 4 January 2015

[4] "Shilp Guru award for Ismail Suleman Khatri". Times of India. November 19, 2012. Retrieved 5 January 2015.

[5] "The man behind the craft". The Hindu. February 17, 2003. Archived from the original on 3 January 2015. Retrieved 5 January 2015.

[6] Chari, Pushpa ,"The Bagh story...". The Hindu, 20 October 2011.

[7] Bechtold T., A. Mahmud-Alia and R. Mussaka. Natural dyes for textile dyeing: A comparison of methods to assess the quality of Canadian golden rod plant material. Dyes and Pigments, 2007, 75(2): 287-293.

[8] Chakraborty, Application of Eco -Friendly Vegetable Dyes on Cotton Fabric. May 11 ,2009

[9] Frigerio, M. Natural dyes. Tinctoria, 1992. 89(12):46-54.

[10] Gulrajani, M.L. and D. Gupta. Natural dyes and their application to textiles. 1992, Pp 81- 96.

[11] M.P. Midday Editor — Bagh Prints artists in Argentina for fourth Bharat Mahotsav (2011).

[12] Sarkar, D., K. Mazumdar and S. Datta. Application of eco-friendly Floral dye on natural fibre: Flax. ManMade Textiles in India, 2006. 49(11): 409-419.

[13] The Craft of Natural Dyeing, by Jenny Dean, Paperback, SRC.

[14] www.enwikipedia.org

[15] www.naturalhandyman.co

\section{AUTHOR BIOGRAPHY}

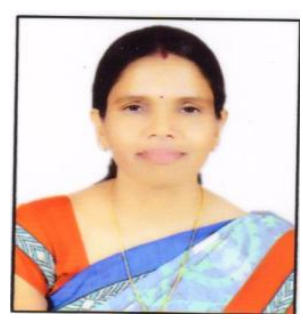

I am working as a assistant professor of History in Government Post Graduate College, Alirajpur (M.P.) and I have a 13 year teaching experience at Govt. P.G. College, Alirajpur, Madhya Pradesh, India

Citation: Kalam Chouhan. "Historical View on Block Printing Technique and its Used in Bagh Print". International Journal of History and Cultural Studies (IJHCS). vol 5, no. 4, 2019, pp. 71-84 doi: DOI: http://dx. doi.org/10.20431/2454-7654.0504006.

Copyright: (C) 2019 Authors. This is an open-access article distributed under the terms of the Creative Commons Attribution License, which permits unrestricted use, distribution, and reproduction in any medium, provided the original author and source are credited. 